\title{
Time Dependent Chloride Diffusion Coefficient in Concrete in Cold Regions
}

\author{
Sijia Chen1, Xiaobing Song1 \& Xila Liu1 \\ ${ }^{1}$ Department of Civil Engineering at Shanghai Jiao Tong University, Shanghai, 200240, China
}

Keywords: Chloride ingress model, diffusion, freeze-thaw cycles, time dependent diffusion coefficient.

Abstract. Chloride and freeze-thaw cycles are two main factors which cause deterioration of reinforced concrete (RC) structure in the cold regions. In this paper, the process of chloride ingress into concrete exposed to freeze-thaw cycles is experimentally researched. From the experimental results, it appears that freeze-thaw cycles make the effective diffusion coefficient become bigger. Based on the experimental data, the concept of developing coefficient was defined to obtain the evolution equation of effective diffusion coefficient. Together with considering the effect of aging of concrete on effective diffusion coefficient, the time dependent diffusion coefficient of concrete in cold regions was obtained.

\section{Introduction}

In cold regions, freeze-thaw attack is one of the main factors which influence durability of RC structures [1]. Meanwhile the chloride, from deicing agent or sea water (for marine and offshore structures), ingress into concrete makes RC structures deteriorate more severely, not only to generate more micro cracks in concrete but also to accelerate the corrosion of the reinforcing steel [2-4]. The combined effects of freeze-thaw cycle and chloride ingress increase the complexity of the durability design and prediction of RC structures located in the seacoast of northern cold region or where deicing salts are used [5-7]. So the research of chloride ingress model of concrete under freeze-thaw cycle is very important for RC structures in cold regions.

There are many papers about chloride penetration into concrete in common climate, but only a few researches about chloride ingress into concrete while suffering freeze-thaw cycles [8-12]. For these few researchers, they mainly focus on comparing the penetration resistance of different type of concrete, but not the prediction method or model of chloride ingress into concrete, which is more significant for durability design such as predicting the time of pitting corrosion of reinforcing steel. However, for the model of chloride ingress into concrete under freeze-thaw cycles, the time dependent diffusion coefficient is the key problem. Only when the time dependent diffusion coefficient is obtained, the model of chloride ingress into concrete under freeze-thaw cycles can be established together with Fick’s second law.

\section{Experimental methods}

As the feasibility of rapid chloride permeability test under freeze thaw cycles is not been verified by enough data, the natural diffusion method is chosen to study the chloride ingress process in this paper.

\subsection{Specimen preparation}

More than 180 concrete specimens $(100 \mathrm{~mm} \times 100 \mathrm{~mm} \times 100 \mathrm{~mm})$ were made.The proportions of the various concrete mixes and the major parameters are listed in Table 1.

Table 1 Mix proportions and major parameters of concrete

\begin{tabular}{|c|c|c|c|c|c|c|c|}
\hline $\begin{array}{l}\text { S } \\
\text { er } \\
\text { ie }\end{array}$ & $\begin{array}{c}\text { Ceme } \\
\mathrm{nt} \\
(\mathrm{kg} / \mathrm{m}\end{array}$ & $\begin{array}{c}\text { Fly } \\
\text { ash } \\
(\mathrm{kg} / \mathrm{m}\end{array}$ & $\begin{array}{c}\text { Water } \\
\text { reduc } \\
\text { er }\end{array}$ & $\begin{array}{l}\text { Water } \\
(\mathrm{kg} / \mathrm{m} \\
3)\end{array}$ & $\begin{array}{c}\text { Coars } \\
\text { e } \\
\text { aggre }\end{array}$ & $\begin{array}{l}\text { Sand } \\
(\mathrm{kg} / \mathrm{m} \\
3)\end{array}$ & $\begin{array}{l}\text { Air- } \\
\text { entrai } \\
\text { ning }\end{array}$ \\
\hline
\end{tabular}




\begin{tabular}{|c|c|c|c|c|c|c|c|}
\hline $\mathrm{S}$ & $\left.{ }^{3}\right)$ & 3 ) & $\begin{array}{l}\text { (\%ce } \\
\text { ment) }\end{array}$ & & $\begin{array}{c}\text { gate } \\
(\mathrm{kg} / \mathrm{m} \\
3)\end{array}$ & & agent \\
\hline A & 338 & 0 & 0.3 & 159 & 1000 & 874 & \\
\hline B & 338 & 0 & 0.3 & 159 & 1000 & 874 & $\begin{array}{c}0.3 \% \\
\text { cemen } \\
t\end{array}$ \\
\hline $\mathrm{C}$ & 271 & 67.6 & 0.3 & 159 & 1000 & 874 & \\
\hline D & 203 & 135.2 & 0.3 & 159 & 1000 & 874 & \\
\hline $\mathrm{E}$ & 320 & 0 & 0.3 & 189 & 1000 & 874 & \\
\hline $\mathrm{F}$ & 256 & 64 & 0.3 & 189 & 1000 & 874 & \\
\hline G & 192 & 128 & 0.3 & 189 & 1000 & 874 & \\
\hline $\mathrm{H}$ & 297 & 0 & 0.3 & 199 & 1000 & 874 & \\
\hline I & 238 & 59.4 & 0.3 & 199 & 1000 & 874 & \\
\hline $\mathrm{J}$ & 178 & 118.8 & 0.3 & 199 & 1000 & 874 & \\
\hline
\end{tabular}

\subsection{Ponding method}

The salt solution was filled in the PVC dikes which were placed on the top surface of the specimens (as shown in Fig. 1).

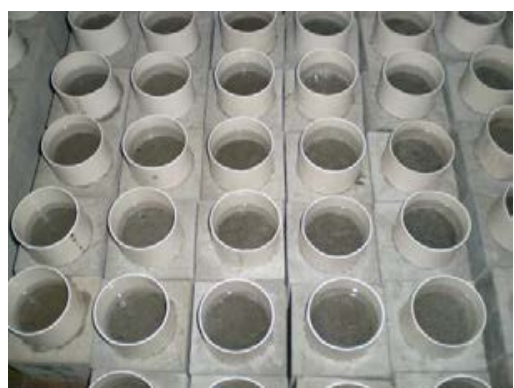

Fig. 1 Specimens with dikes placed on the top surface

\subsection{Salt solution}

From the relationship between freezing point and concentration of calcium chloride solution as in Fig. 2, the main concentration of $\mathrm{CaCl}_{2}$ solution was chosen to be $29 \%$.

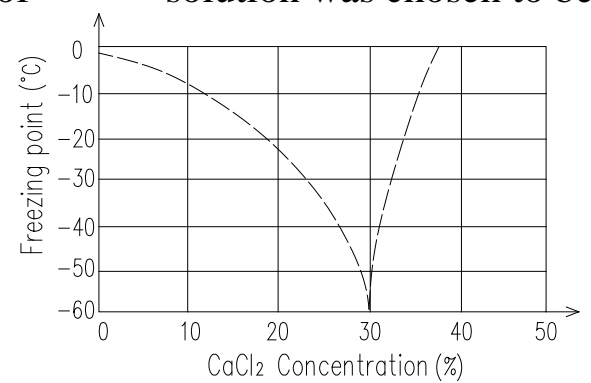

Fig. 2 Relationship between freezing point and concentration of calcium chloride solution

\subsection{Freeze-thaw test}

After dikes placed on the top surface, the specimens were moved into the freeze-thaw chambers(as shown in Fig. 3), and rapid freezing-thawing was carried out according to ASTM C666[13]. 


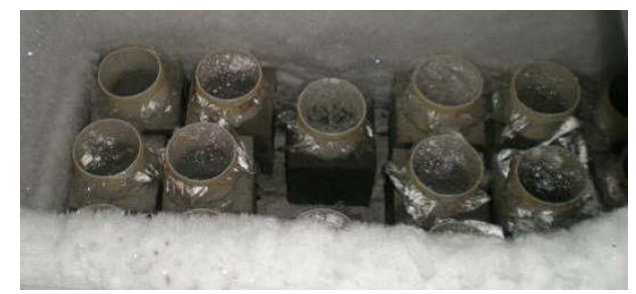

Fig. 3 Specimens being frozen

\subsection{Chloride profiles}

After some freeze-thaw cycles, samples from incremental depths were taken by sawing slices and analyzed for chloride concentration, as shown in Fig. 4.
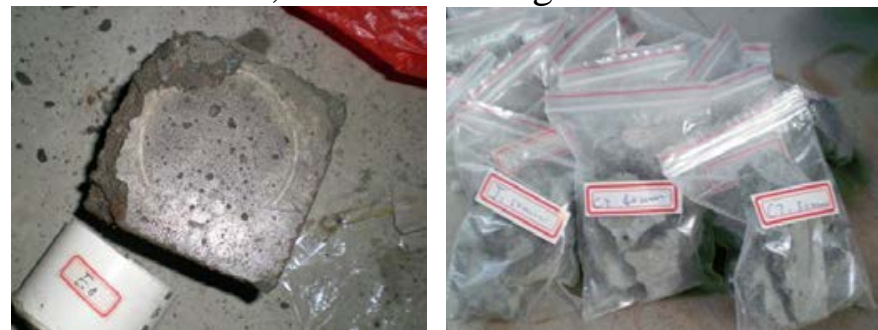

Fig. 4 Specimen after freeze-thaw cycles and sawing slices

\section{Results and Discussion}

\subsection{Experimental De}

From the experiment, the effective diffusion coefficient (De) of each specimen was obtained. Also, the relationship between De and freeze thaw cycles for each type concrete was obtained, as shown in Fig. 6.

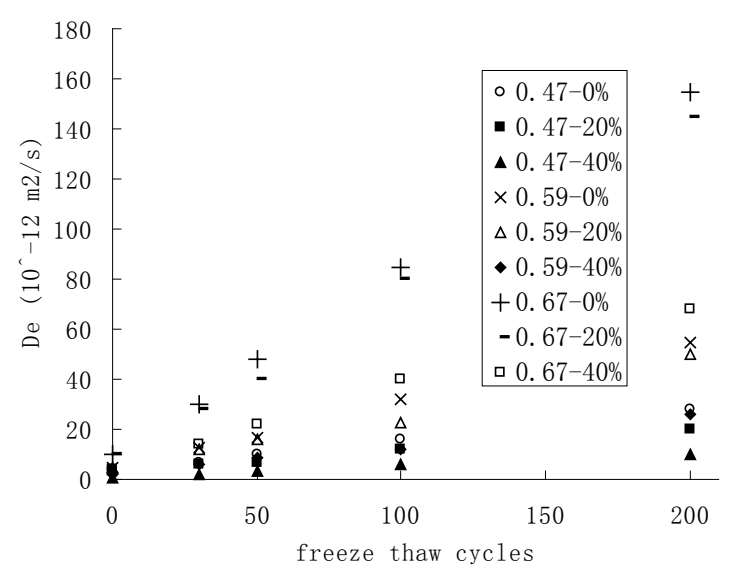

Fig. 5 Relationship between De and freeze thaw cycles for different type of concrete

\subsection{Model building of chloride ingress into concrete under freeze thaw cycles}

\subsubsection{Developing coefficient and evolution equation of De}

In order to research the process of chloride ingress into concrete under freeze thaw cycles, the relationship between De and freeze thaw cycles should be obtained first. For this purpose, in this paper, the concept of developing coefficient of De (designated as $\mathrm{Kd}$ ) is defined. From Fig. 6, it's apparent that for each type of concrete, De increases as freeze thaw cycles increasing. So, the increment of De in one freeze-thaw cycle can be defined as the developing coefficient of De, which can be expressed as following equation:

$$
K_{d(N)}=D e_{(N+1)}-D e_{(N)}
$$

Therefore, the evolution equation for De can be derived: 


$$
D e_{(N)}=D e_{0}+\sum_{i=1}^{N} K_{d(i)}
$$

Where, $D e_{(N)}$ is the effective diffusion coefficient of concrete after a certain number $(\mathrm{N})$ of freeze-thaw cycles, $N$ is the number of freeze-thaw cycles, $D e_{0}$ is the initial effective diffusion coefficient.

From the experimental data in Fig. 6, we can find that De increases approximately linearly as freeze thaw cycles increasing. So, it's reasonable to use the approach of linear regression on De and freeze-thaw cycles to obtain the average developing coefficient $\left(K_{d a}\right)$. The linear regression analysis results for average developing coefficient are shown in Table 2.

$4 K_{d a}$ values of different type of concrete

\begin{tabular}{|c|c|c|c|}
\hline $\begin{array}{l}\text { ratio } \\
\text { Fly ash }\end{array}$ & 0.47 & 0.59 & 0.67 \\
\hline $0 \%$ & $1.13 \mathrm{E}-13$ & $2.43 \mathrm{E}-13$ & 7.18E-13 \\
\hline $20 \%$ & 7.30E-14 & 2.04E-13 & 6.65E-13 \\
\hline $40 \%$ & 4.20E-14 & $1.15 \mathrm{E}-13$ & 3.09E-13 \\
\hline 0\%（air-entrained） & 9.62E-14 & & \\
\hline
\end{tabular}

From the data in Table 2, it's apparent that the values of $K_{d a}$ increase with increasing W/C ratio and decreasing fly ash content. It means that increasing $\mathrm{W} / \mathrm{C}$ ratio and decreasing fly ash content can accelerate the degradation process of concrete under freeze-thaw cycles. Also, from comparing $K_{d a}$ values of specimens with and without air-entrainment, it is found that the air entrainment can improve the frost resistance of concrete.

So, with the average developing coefficient $\left(K_{d a}\right)$ instead of developing coefficient $\left({ }^{K_{(i)}}\right)$ in formula(2), the following equation can be easily derived:

$$
D e_{(N)}=D e_{0}+K_{d a} \times N
$$

While formula (3) is used to predict De of concrete in practical engineering, the number of natural freeze thaw cycles should be equivalently transformed to the number of rapid freeze thaw cycles in laboratory first. And then, the relationship between time $\mathrm{t}$ and $\mathrm{N}$ should be established. Finally, the evolution equation can be derived:

$$
D e_{(t)}=D e_{0}+K_{d a} \times N_{(t)}
$$

Formula (4) is simplified evolution equation for De of concrete under freeze-thaw cycles, which can be used in practical engineering.

\subsubsection{The effect of ageing of concrete on De}

Observations at structures suggest that diffusion coefficient of concrete is not a constant value over time due to a gradually increasing degree of hydration[14]. Consideration must be given to the ability of the cementitious system to refine its pore structure as it matures, thereby decreasing transport rates. Due to continued hydration of cement, the porosity is reduced, which results in a reduced diffusion coefficient. Based on many years of research at concrete exposed to an outdoor climate, an equation including the effect of ageing of concrete on diffusion coefficient is given [1517]:

$$
D(t)=D_{0} t^{-n}
$$

Where, $D(t)$ is time-dependent diffusion coefficient, $D_{0}$ is initial diffusion coefficient, $t$ is time (year), $n$ is ageing parameter. 


\subsubsection{Time dependent De of concrete in cold regions}

For concrete in cold regions, both freeze thaw cycles and ageing effect should be considered on De. So, in this paper, the time dependent model of De is assumed as follows:

$$
D e_{(t)}=\left(D e_{0}+K_{d a} N_{(t)}\right) \times\left(\frac{1}{t}\right)^{n}
$$

Where, $D e_{(t)}$ is time dependent effective diffusion coefficient, $N$ is the number of freeze-thaw cycles, $D e_{0}$ is the initial effective diffusion coefficient, $K_{d a}$ is developing coefficient, $N_{(t)}$ is equivalent number of freeze thaw cycles, $t$ is time (year), $n$ is ageing parameter.

With the time dependent model of De and Fick's second law, the model of chloride ingress into concrete in cold regions can be established.

\section{Conclusions}

In this paper, the experiment of specimens suffered both freeze-thaw cycles and chloride ingress were carried out. From the experimental results, it's apparent that after freeze-thaw cycles, the effective diffusion coefficient will increase. As w/c ratio increasing and fly ash content decreasing, effective diffusion coefficient increases. Based on the experimental data, the concept of developing coefficient was defined to obtain the evolution equation of effective diffusion coefficient. Together with considering the effect of aging of concrete on effective diffusion coefficient, the time dependent diffusion coefficient of concrete in cold regions was obtained.

\section{Acknowledgements}

This work was financially supported by the National Natural Science Foundation of China (No. 50678101), and Natural Science Foundation of Shanghai (No. 11ZR1417400). Corresponding author is Xiaobing Song(songxb2014@163.com).

\section{References}

1. Mehta, K., Durability of Concrete-The Zigzag Course of Progress. Indian Concrete Journal, 2006. 80(8): p. 9-16.

2. Chindaprasirt, P. and W. Chalee, Effect of sodium hydroxide concentration on chloride penetration and steel corrosion of fly ash-based geopolymer concrete under marine site. Construction and Building Materials, 2014. 63(0): p. 303-310.

3. Wang, K., D.E. Nelsen, and W.A. Nixon, Damaging effects of deicing chemicals on concrete materials. Cement and Concrete Composites, 2006. 28(2): p. 173-188.

4. Van den Heede, P., J. Furniere, and N. De Belie, Influence of air entraining agents on deicing salt scaling resistance and transport properties of high-volume fly ash concrete. Cement and Concrete Composites, 2013. 37(0): p. 293-303.

5. Hamze, Y., Concrete Durability in Harsh Environmental Conditions Exposed to Freeze Thaw Cycles. Physics Procedia, 2014. 55(0): p. 265-270.

6. Sun, W., et al., Effect of chloride salt, freeze-thaw cycling and externally applied load on the performance of the concrete. Cement and Concrete Research, 2002. 32(12): p. 1859-1864.

7. Kuosa, H., et al., Effect of coupled deterioration by freeze-thaw, carbonation and chlorides on concrete service life. Cement and Concrete Composites, 2014. 47(0): p. 32-40.

8. Chung, C.-W., C.-S. Shon, and Y.-S. Kim, Chloride ion diffusivity of fly ash and silica fume concretes exposed to freeze-thaw cycles. Construction and Building Materials, 2010. 24(9): p. 1739-1745.

9. Jin, Z.-Q., et al., Chloride penetration and pore structure of air entrained concrete subjected to freeze-thaw cycles. Zhongnan Daxue Xuebao (Ziran Kexue Ban)/Journal of Central South University (Science and Technology), 2012. 43(5): p. 1963-1968. 
10. Kuosa, H., et al., Effect of coupled deterioration by freeze-thaw, carbonation and chlorides on concrete service life. Cement \& Concrete Composites, 2014. 47: p. 32-40.

11. Zhao, J., et al., Influences of freeze-thaw cycle and curing time on chloride ion penetration resistance of Sulphoaluminate cement concrete. Construction and Building Materials, 2014. 53: p. 305-311.

12. Saito, M., M. Ohta, and H. Ishimori, Chloride permeability of concrete subjected to freeze-thaw damage. Cement and Concrete Composites, 1994. 16(4): p. 233-239.

13.ASTM, Standard Test Method for Resistance of Concrete to Rapid Freezing and Thawing. 2003, ASTM International.

14. Luca Bertolini, B.E., Pietro Pedeferri,Rob Polder, Corrosion of Steel in Concrete. 2004: WILEY-VCH.

15. Bamforth, P.B., The derivation of input data for modeling chloride ingress from eight year UK coastal exposure trials. Magazine of Concrete Research, 1999. 51(2): p. 87-96.

16. K, T. and M. S, Quality and cover thickness of concrete based on the estimation of chloride penetration in marine environments. Concrete in Marine Environment, 1988: p. 381-400.

17. S., M.P. and B.T. Molloy, Prediction of long term chloride concentration in concrete. Materials and Structures, 1994. 27(168): p. 338-346. 